\title{
A importância das tecnologias digitais assistivas aliadas do trabalho do professor de língua inglesa com alunos públicos-alvo da educação especial
}

\author{
The importance of the assistive digital technologies associated from the english teacher's work with \\ students targeted to special education \\ La importancia de las tecnologías de asistencia digital aliadas al trabajo del maestro de inglés con \\ los estudiantes que son el público objetivo de la educación especial.
}

Recebido: 07/01/2022 | Revisado: 11/01/2022 | Aceito: 14/01/2022 | Publicado: 16/01/2022

\author{
Simone Carloto Frasson \\ ORCID: https://orcid.org/0000-0002-5282-7398 \\ Universidade Franciscana, Brasil \\ E-mail: sifrasson@hotmail.com \\ Valeria Iensen Bortoluzzi \\ ORCID: https://orcid.org/0000-0003-4268-2209 \\ Universidade Franciscana, Brasil \\ E-mail: valeria.bortoluzzi@gmail.com \\ Taís Steffenello Ghisleni \\ ORCID: https://orcid.org/0000-0002-5405-9492 \\ Universidade Franciscana, Brasil \\ E-mail: taisghisleni@ufn.edu.br
}

\begin{abstract}
Resumo
O presente trabalho tem, como objetivo principal, apresentar uma reflexão sobre o uso de Tecnologias Assistivas (TA) enquanto uma ferramenta de apoio ao trabalho do professor de língua inglesa que possui, em sua sala de aula, alunos públicos-alvo da Educação Especial. Em vista disso, foi realizada uma análise das Tecnologias Assistivas utilizadas pelos professores dessa área, bem como foi feito um levantamento das tecnologias que estão disponíveis para contribuir no trabalho do professor de língua inglesa com alunos público-alvo da Educação Especial. A metodologia do presente trabalho, por sua vez, foi fundamentada a partir da abordagem qualitativa e se pautou em estudos de referenciais teóricos de autores como a Martha Gabriel, entre outros. Diante disso, a investigação possibilitou conhecer o cenário das pesquisas sobre as Tecnologias Assistivas e os resultados positivos do uso dessa tecnologia no que se refere à melhora da qualidade de vida dos alunos com necessidades especiais, ou seja, alunos públicos alvos da Educação Especial.
\end{abstract}

Palavras-chave: Educação inclusiva; Aprendizagem da língua inglesa; Tecnologia digital.

\begin{abstract}
The main objective of this word is to present a reflection about the use of Assistive Technologies (TA) as a support tool for the work of the English language teacher who has in his classroom students who are the target audience of Special Education. In view of this, an analysis of the Assistive Technologies used by teachers in this area was carried out as well as a survey of the technologies that are available to contribute to the work of the English language teacher with students who are the target audience of Special Education. The methodology of this work, in turn was based on a qualitative approach and was based on studies of theoretical references of authors such as Martha Gabriel among others. That said, the investigation made it possible to know the scenario of research on Assistive Technologies and the positive results of the uses of this technology in terms of improving the quality of life of students with special needs, that is target public students of Special education.
\end{abstract}

Keywords: Inclusive education; English language learning; Digital technology.

\section{Resumen}

El objetivo principal del presente trabajo es presentar una reflexión sobre el uso de las Tecnologías Asistivas (AT) como herramienta de apoyo al trabajo del docente de lengua inglesa que tiene en su aula alumnos públicos-objetivo de Educación Especial. Ante esto, se realizó un análisis de las Tecnologías Asistivas que utilizan los docentes en esta área, así como un relevamiento de las tecnologías que están disponibles para contribuir al trabajo del docente de lengua inglesa con los alumnos que son el público objetivo de Educación Especial. La metodología de este trabajo, a su vez, se basó en un enfoque cualitativo y se basó en estudios de referencias teóricas de autores como Martha Gabriel, entre otros. Delante de eso, la investigación permitió conocer el escenario de la investigación en Tecnologías Asistivas y los 
resultados positivos del uso de esta tecnología en términos de mejora de la calidad de vida de los estudiantes con necesidades especiales, es decir apuntar a estudiantes públicos de Educación Especial.

Palabras clave: Educación integrada; Aprendizaje del idioma inglés; Tecnología digital.

\section{Introdução}

As tecnologias têm ocupado um espaço importante em nossas vidas, na qual exercem influências em diferentes esferas. Além de fazer parte do nosso dia a dia, tanto para as atividades de lazer, quanto para o mercado de trabalho, como uma ferramenta importantíssima, tornou-se, ainda, uma grande aliada no âmbito educacional. Esse dispositivo tecnológico, além de beneficiar a educação, está transformando o aprendizado e, assim, disseminando e ampliando a informação e o conhecimento com mais rapidez. Com isso, há uma renovação da relação entre os professores e alunos.

Os procedimentos metodológicos estão relacionados a uma pesquisa estruturalmente bibliográfica, a qual teve sua construção formada a partir de diversos autores e de uma temática voltada ao enfoque da educação ligada à informatização, mais precisamente a Tecnologia Assistiva. A metodologia do trabalho, por sua vez, foi fundamentada a partir da abordagem de cunho qualitativo de pesquisa, pois se apresenta como um direcionamento capaz de promover a reflexão sobre os meios facilitadores na aprendizagem e no convívio social de alunos com algum tipo de deficiência.

Em vista disso, no capítulo a seguir, procuraremos destacar aspectos de maior relevância para o desenvolvimento desse trabalho ao nos referirmos à tecnologia na educação. Após, será apresentada a Tecnologia Assistiva na rede de ensino regular para alunos públicos-alvo da Educação Especial. Já no capítulo 3, será estabelecida uma discussão acerca da Tecnologia Assistiva e do ensino da língua inglesa em sala de aula em que haja educação inclusiva. Na sequência, serão feitas as considerações finais a respeito dessa pesquisa.

\section{Metodologia}

A metodologia de pesquisa é de caráter qualitativo e foi organizada, basicamente, com o delineamento do estudo, na qual, no primeiro item foi abordada a tecnologia na educação, com suporte das diretrizes e bases da educação nacional e da autora Marta Gabriel. A autora defende o uso das tecnologias na educação, com o intuito de trazer benefícios aos alunos e professores (Gabriel, 2013). Após, no item 4, cujo o título é "A tecnologia assistiva na educação regular de ensino para alunos público alvo da educação especial", teve respaldo na Base Nacional Comum Curricular, na Lei Brasileira de Inclusão da Pessoa com Deficiência, em que considera a tecnologia assistiva uma aliada do professor, no caso de inclusão escolar, de forma a promover a autonomia e independência desses alunos. E por último, no item 5, trata-se da "Tecnologia Assistiva e o Ensino de Língua Inglesa em Sala de Aula com Educação Inclusiva”. Nesse item, Martins (2020) ressalta a importância de ser ensinada a língua inglesa para alunos públicos-alvo da Educação especial, aliada à tecnologia assistiva como forma de ampliar suas oportunidades de aprendizado e desenvolver formas de reconhecer o mundo não apenas na língua materna.

\section{Tecnologia na Educação}

A Lei 9394/96 da educação, a qual estabelece as Diretrizes e Bases da Educação Nacional, compreende os processos formativos que se desenvolvem na vida familiar, na convivência humana, no trabalho, nas instituições de ensino e pesquisa, nos movimentos sociais, na organização da sociedade civil e nas manifestações culturais (BRASIL, 1996).

Apesar de a educação ser realizada com poucas alterações, durante os anos, quanto ao seu formato, a inserção da tecnologia, no contexto educacional, é um caminho sem volta. No intuito de beneficiar o aluno, a revolução digital já é uma realidade e está presente nos avanços tecnológicos que transformaram diversos aspectos da sociedade. De acordo com Gabriel (2013), a internet tornou-se a principal plataforma planetária de comunicação, entretenimento, negócios, relacionamento, 
aprendizagem e infraestrutura, em pouco mais de uma década. Tal ferramenta é responsável por uma nova roupagem da humanidade globalizada.

É perceptível que nossas vidas passaram por um impacto, gerado pelas tecnologias digitais, nunca antes visto na história da humanidade. Estamos vivendo uma revolução digital, chamada Era Digital. Sendo, assim, o avanço acelerado das tecnologias digitais têm apresentado alterações significativas no modo de entendermos e percebermos o mundo. Contudo, precisamos pensar sobre em que aspectos a revolução tecnológica se torna importante para nós, já que, se não soubermos utilizá-la em nosso benefício, não terá validade nenhuma. O que realmente importa é sabermos o que devemos fazer com a tecnologia e detectarmos como ela pode melhorar nossas vidas.

"Em toda revolução tecnológica, as pessoas tendem a ficar encantadas com a tecnologia em si, pois, como dizia o escritor Arthur C. Clarke, "qualquer tecnologia suficientemente avançada é indistinguível de magia". No entanto, depois que o encantamento passa, o foco passa a ser em que benefícios tais tecnologias podem nos trazer - quais possibilidades e ameaças cada uma delas apresentam". (Gabriel, 2013, p. 20).

Após esse deslumbramento digital, passamos a procurar mais informações em palestras e livros com o intuito de que pudéssemos entender como usar todo o aparato digital para vivermos melhor, seja produzindo conhecimento e informações, relacionando-nos e, até mesmo, para nos educarmos de forma mais adequada. Segundo Gabriel (2013), são muitas as possibilidades, mas também os desafios promovidos pela tecnologia.

Em vista disso, Gabriel (2013, p.20) salienta que "não temos mais como resolver as dificuldades de hoje com as soluções de ontem". Assim, é preciso buscar a informação e o aprendizado. As mudanças que ocorrem no contexto atual, são geradas pelo surgimento de novas tecnologias da informação e da comunicação. E por conseguinte, o mesmo ocorre no âmbito educacional. Assim, é preciso buscar a informação, conjuntamente com o aprendizado. A partir disso, a autora defende a ideia de que é preciso capacitar as pessoas para o uso das ferramentas oferecidas, sugerindo que seja realizado um investimento na capacitação das pessoas para que elas aprendam a usar os meios tecnológicos.

A partir de tal compreensão, acreditamos que o educador precisa considerar a mudança que as tecnologias trazem a vida das pessoas, inclusive dos alunos e no quotidiano da sala de aula. Com isso, consoante com o ponto de vista de Gabriel (2013), Miranda, M.; Souza, A.; Oliveira, J. (Miranda, 2020) apontam que a formação dos educadores/professores se torna fundamental em todo e qualquer processo em que seja realizada a adequação da integração das tecnologias no contexto escolar. Dessa forma, assim que os educadores/professores aprendem a usar a tecnologia, no contexto escolar, ou seja, em sua sala de aula, com as crianças reais e de acordo com objetivos igualmente reais, eles se beneficiam de muito mais possibilidades dessa formação. Ao possibilitar essa interação entre a escola, os alunos, professores e conteúdo, as novas tecnologias avançam significativamente no processo educacional. Em outras palavras, os docentes ajudam a melhorar a qualidade dos contextos de aprendizagem em que desenvolvem suas atividades.

Alguns autores, tais como Moran, 1995; Belloni, 2005; Bianchi; Pires; Vanzin, 2008; Kenski, 2007; Silva, 2011; Cruz; Bizelli, 2014, consideram que educadores precisam educar-se para utilizar inovações tecnológicas, desenvolvendo e aperfeiçoando metodologias que promovam aprendizagem. Isso deve ser acompanhado de condições adequadas de formação continuada, estruturas, recursos, tempo e remuneração. (Darido, Bizelli, 2015).

Já Gabriel (2013) observa que, além da capacitação dos professores e profissionais da educação nas instituições de ensino, algumas etapas devem ser levadas em consideração para a implantação dos recursos tecnológicos, e esse processo exige muito mais do que a simples aquisição de computadores e laboratórios de informática, prevendo, do mesmo modo, o entendimento de como devem ser empregados esses recursos. Diante disso, além de definir quais tecnologias são mais adequadas a cada instituição, em um primeiro momento, torna-se necessário o conhecimento das ferramentas a serem utilizadas em outro momento, isto é, ter conhecimento técnico-pedagógico da tecnologia que será disponibilizada para o aluno e professor. 
"Um dos grandes problemas atuais no mercado e nas instituições é a falta de educação digital e de pensamento estratégico em relação às mídias digitais. Para que o segundo aconteça, é necessário investimento no primeiro. Depois da capacitação, o passo natural é o investimento em automatização e ferramentas que possibilitem o aumento da produtividade. No entanto, não adianta investir em ferramentas e automação antes de capacitar as pessoas, pois isso seria o mesmo que investir em um avião para ser usado por quem não sabe pilotar; em outras palavras, os resultados podem ser desastrosos. Tecnologia não é diferencial, mas o modo como a utilizamos, sim” (Gabriel, 2013, p;26).

Em vista disso, o uso da tecnologia, no ensino, tornou-se imprescindível para que o processo educacional ocorra e ofereça aos alunos melhor formação, visto que essa oferece muitas possibilidades, as quais viabilizam diferentes alternativas e concepções pedagógicas, que vão além de meras tarefas e dos suportes usados na realização de atividades. Diante dessa realidade, as escolas tiveram que se adaptar e incluir a tecnologia no ensino, de forma a atenderem o novo perfil do estudante, o qual passou a ser mais dinâmico, crítico e conectado.

Em tempos de pandemia, que estamos vivenciando, os desafios são muitos, e as instituições precisaram se adaptar e, com isso, transformar o método tradicional de ensino, adotando soluções tecnológicas. No ambiente educacional, a tecnologia digital tornou-se uma alternativa de ensino e, muitas vezes, resultou em uma mudança fundamental para a educação. Ao se pensar no método tradicional de ensino, baseado nas concepções de retenção, memorização e repetição de informações, percebemos que perdem cada vez mais o sentido, dando lugar às novas tecnologias, visto que as mudanças, transformações e avanços ocorrem de forma cada vez mais rápida (Galvão Filho, 2012).

A tecnologia está, cada vez mais, inserida no ambiente escolar, contribuindo para possibilitar uma melhor qualidade ao ensino. Porém, um outro tipo de reflexão deve ser feito em benefício do aluno público-alvo da Educação Especial.

Ao pensarmos nesse público da Educação Especial, é notório que a tecnologia avançou muito, de forma a fornecer recursos que possibilitem a independência e a autonomia desses alunos, independente de terem algum impedimento de natureza física, mental, intelectual ou sensorial. Nesse contexto, as tecnologias assumem a função da chamada Tecnologia Assistiva, que vem sendo estudada, nos dias de hoje, e aponta para um ambiente enriquecedor para os alunos públicos-alvo da Educação Especial, otimizando as possibilidades desses estudantes, também, no percurso de construção de uma escola inclusiva (Galvão, 2012).

\section{Tecnologia Assistiva na Educação Regular de Ensino para Alunos Público Alvo da Educação Especial}

Segundo a Base Nacional Comum Curricular, a BNCC, a Educação Especial faz parte da educação que se dispõe ao atendimento de pessoas que apresentam algum tipo de necessidade educativa especial ou algum tipo de deficiência.

A educação, a partir do início dos anos 1990, com a Lei № 8069, passou a considerar a importância de a Educação Especial atuar, preferencialmente na rede regular de ensino. Assim, ela passou a atuar em instituições de ensino regular ou em ambientes especializados, como, por exemplo, escolas para surdos, para cegos ou escolas que atendessem pessoas com alguma deficiência intelectual.

Já a Lei de Diretrizes e Bases da Educação no 9396 (LDB), de 1996, no capítulo V, define a Educação Especial como um ramo da educação escolar a qual deve ser oferecida, principalmente, na rede regular de ensino, para os alunos que apresentam algum tipo de deficiência, transtornos globais do desenvolvimento e, também, alunos que tenham altas habilidades ou superdotação. Eles devem ter acesso igualitário aos benefícios dos programas sociais suplementares disponíveis para o respectivo nível do ensino regular. Além disso, esses alunos devem receber, quando necessário, serviços especializados, que os auxiliem nos obstáculos encontrados em seus processos de aprendizado pleno. Isso tudo deve ser realizado visando à efetiva integração desses estudantes na vida em sociedade e no mercado de trabalho. (BRASIL, 1996).

A Educação Especial Inclusiva é um método pedagógico que concilia as características do ensino regular com as características da Educação Especial, de maneira a promover, assim, a integração entre crianças com diferentes necessidades. Nessa perspectiva, a Lei Brasileira de Inclusão da Pessoa com Deficiência, No 13.146, aprovada em 2015, conhecida como 
Estatuto da Pessoa com Deficiência, Art. I, assegura e promove, em condições de igualdade, a inclusão social e a cidadania, assegurando os exercícios dos direitos e das liberdades fundamentais para pessoas com deficiência. De acordo com essa lei, a pessoa com deficiência é aquela que apresenta, ao longo de sua vida, algum impedimento de natureza física, mental, intelectual ou sensorial, de modo que possa ter obstáculos que a impeçam de participar, plena e efetivamente, na sociedade, em igualdade de condições com as outras pessoas (BRASIL, 2015).

No Cap. IV, do Direito à Educação, essa lei prevê a educação como um direito que constitui a pessoa com deficiência, devendo ser assegurada em um sistema educacional inclusivo em todos os níveis e aprendizado, ao longo de sua vida, no intuito de que consiga alcançar o máximo possível de desenvolvimento de seus talentos e de suas habilidades físicas, sensoriais, intelectuais e sociais, segundo suas particularidades. Para tanto, fica assegurado o aprimoramento dos sistemas educacionais, permitindo o acesso e a permanência desses alunos na escola. No Art. 28, inciso V, consta a adoção de medidas individualizadas e coletivas em ambientes que maximizem o desenvolvimento acadêmico e social do alunado com deficiência. Para que isso se realize, ficam asseguradas as pesquisas em prol do desenvolvimento de novos métodos e técnicas pedagógicas, de materiais didáticos, de equipamentos e de recursos de Tecnologias Assistivas, bem os estudos a respeito da usabilidade pedagógica desses recursos (BRASIL, 2015).

A inserção de alunos com algum tipo de deficiência, na Rede Municipal de ensino, foi instituída pela Lei Brasileira de Inclusão de Pessoa com Deficiência (BRASIL, 2015), com o intuito de assegurar e promover, igualmente, os direitos e liberdades de cada um. Segundo essa lei, a pessoa com deficiência é aquela que possui algum tipo de impedimento de longo prazo, seja ele de natureza intelectual, física, mental ou sensorial (BRASIL, 2015).

A inserção desses alunos, por sua vez, fez as escolas buscarem recursos com o intuito de que professores, funcionários e alunos pudessem se adaptar a essa nova realidade, de modo a ser proporcionada uma boa integração entre todos. Já aos alunos públicos-alvo da Educação Especial, faz-se necessário oferecer, além de um Atendimento Educacional Especializado (AEE), instrumentos para suas necessidades, como o uso da Tecnologia Assistiva (T.A.), contribuindo para a permanência deles na escola.

A Lei Brasileira de Inclusão da pessoa com deficiência, em seu Art. III, apresenta avanços importantes em prol do aluno com necessidades educacionais especiais, tais como a Tecnologia Assistiva, também chamada de ajuda técnica. Por meio dessa, são disponibilizados produtos, equipamentos, dispositivos, recursos, metodologias, estratégias, práticas e serviços que ajudem a promover a funcionalidade para que os alunos com deficiência ou mobilidade reduzida, de maneira a terem autonomia e independência, bem como qualidade de vida e inclusão social (BRASIL, 2015).

O conceito de Tecnologia Assistiva foi aprovado pelo Comitê de Ajudas Técnicas (CAT), que estuda essa área de conhecimento no âmbito da Secretaria Especial dos Direitos Humanos da Presidência da República (SEDH/PR):

“Tecnologia Assistiva é uma área do conhecimento, de característica interdisciplinar, que engloba produtos, recursos, metodologias, estratégias, práticas e serviços que objetivam promover a funcionalidade, relacionada à atividade e participação de pessoas com deficiência, incapacidades ou mobilidade reduzida, visando sua autonomia, independência, qualidade de vida e inclusão social”. (Cat, 2007).

Os recursos da Tecnologia Assistiva são muito amplos, vão além de uma simples bengala improvisada, feita com um pedaço de pau, um aparelho de ampliação, utilizado por pessoas com surdez, até um veículo adaptado para pessoas com deficiência (Galvão, 2012).

Portanto, a Tecnologia Assistiva (T.A.), no âmbito educacional, é um termo relativamente novo, que consiste em identificar os recursos tecnológicos empregados no intuito de proporcionar ou de ampliar as habilidades de pessoas com algum tipo de deficiência e, com isso, proporcionar a elas uma vida mais independente. Seu objetivo consiste em romper barreiras, as quais podem ser sensoriais, cognitivas ou motoras. 
Em suma, o trabalho do professor com alunos públicos-alvo da Educação Especial, os quais dispõem da Tecnologia Assistiva, torna-se de grande valia, uma vez que ele tema, ao seu alcance, estratégias, metodologias e recursos com o objetivo de ampliar a participação dos alunos que apresentam algum tipo de deficiência ou mobilidade reduzida. Assim, esses estudantes têm a possibilidade de adquirir autonomia na escola e fora dela, além de ampliarem e otimizarem suas possibilidades de aprendizagem (Santana, Santos e Pereira, 2012).

Para que essas práticas e serviços ocorram em benefício do aluno, incluindo-o no processo de ensino e aprendizagem oferecido pela escola, torna-se necessário o acompanhamento do estudante ao utilizar qualquer tipo de recurso tecnológico, pois ele poderá precisar de uma adaptação desses recursos. Além disso, é muito importante que o professor e toda a equipe escolar sejam capacitados para a utilização desses recursos, ou seja, há uma necessidade de que todos os envolvidos tenham um treinamento e todo apoio necessário para que a T.A. seja usada de forma correta, proporcionando seu emprego adequado em prol do usuário (Santana, Santos e Pereira, 2012).

A aplicação das Tecnologias Assistivas gera muitas vantagens para quem faz uso delas. São inúmeras ferramentas, utensílios e recursos empregados de modo a favorecer o desempenho autônomo durante as atividades diárias. Na área educacional, esse incontável número de recursos é simples e de baixo custo, podendo ser incluídos nas salas de aulas inclusivas. Para ilustrar esses recursos, temos: suportes para visualização de textos ou livros; fixação do papel ou caderno na mesa com fitas adesivas; pré-bengalas com cano de PVC; pulseira imantada e chapa de metal sob a folha (auxilia a inibir os movimentos involuntários); números e letras imantados ou com velcro, adaptadores para tesouras; engrossadores de lápis ou caneta confeccionados com esponjas enroladas e amarradas, ou punho de bicicleta ou tubos de PVC "recheados" com epóxi ${ }^{1}$; substituição da mesa por pranchas de madeira ou acrílico, fixadas na cadeira de rodas; órteses moldável (feita de EVA, metal, madeira ou massa durepoxi), entre outras. Esses recursos devem ser adaptáveis conforme a necessidade de cada aluno (Galvão, 2012). Muitos deles, necessários no ambiente escolar, atenderão os alunos em relação à alimentação, à higiene pessoal, à mobilidade, à leitura, ao ato de escrever, à comunicação, ao aprendizado. (Santana, Santos e Pereira, 2012).

Ainda nessa perspectiva, existem, no ramo da Tecnologia Assistiva, as tecnologias de ponta, as quais são cada vez mais usadas como recursos ou instrumentos de intervenção, que auxiliam os alunos com necessidades educacionais especiais. Esses tipos de tecnologias são os hardwares e softwares especialmente idealizados para tornar o computador mais acessível, tais como: os teclados modificados (com colmeia); os teclados virtuais, com varredura; os mouses especiais e os acionadores diversos (acionados por movimento de cabeça ou movimento ocular). Dentre as deficiências existentes, a deficiência visual é uma delas. No caso dessa necessidade especial, a Tecnologia Assistiva (T.A.) surge como meio de oferecer novas oportunidades ao aluno que a apresente, com o uso de diversos recursos, tais como o braille, softwares de ampliação de tela, lupas eletrônicas, teclados com letra ampliada. Além disso tudo, os alunos com deficiência visual podem contar com o auxílio do Desenvolvimento Óptico de Caracteres (DOC), o qual faz um escaneamento do texto em papel e converte-o em formato digital para, depois, convertê-lo em áudio. Assim, a pessoa com deficiência visual pode ter acesso a todo material impresso, desde revistas, jornais, livros e imagens, já que eles podem ser descritos por sintetizador de voz eletrônico. (Blog Freedom, 2021).

No âmbito da comunicação, a Tecnologia Assistiva faz uso de dispositivos que auxiliam as pessoas com dificuldade na fala ou na escrita. Entre as ferramentas mais comuns, está a prancha, que consiste em um conjunto de letras, símbolos e números em que a pessoa aponta para eles e vai formando a palavra. Existem, também, equipamentos de voz ou softwares que permitem que a pessoa se comunique por meio de voz robótica. No caso das pessoas com deficiência auditiva, elas têm o benefício do uso de aparelhos de surdez, telefones com teclado, equipamento infravermelho, sistema de alerta táctil-visual, entre outros, os quais possibilitam sua comunicação. Diante disso, o acesso ao computador ficou facilitado para pessoas com deficiências sensoriais, tanto auditivas como visuais. Nesse caso, muitos dispositivos estão disponíveis, a exemplo de: teclados modificados, mouse 
adaptados, com acionadores diversos, recurso de reconhecimento de voz, impressoras em braille, softwares que captam movimentos de cabeça, de olhos e entendem os comandos.

Outrossim, cada vez mais, existem tecnologias e recursos para melhorar a qualidade de vida dos autistas. Pode-se notar o autismo enquanto a criança assiste a filmes, por exemplo. Na universidade de Ben-Gurion do Negev, em Israel, medem-se os padrões do olhar da criança enquanto ela assiste a filmes que tenham interações sociais. Há inúmeras formas de Tecnologias Assistivas que podem ajudar os autistas, seja em suas tarefas diárias, como comer, vestir-se, como também em se tratando de recursos de comunicação aumentativa. Os autistas, dependendo do grau, muitas vezes, apresentam dificuldades motoras e, portanto, podem precisar de teclados adaptados e/ou softwares, os quais atendam outras necessidades.

Percebe-se, assim, uma ampla relação entre as Tecnologias Assistivas e a educação inclusiva. Em suma, o conjunto dessas ferramentas, aliadas à prática do professor, contribui para ampliar as oportunidades de acesso de todos ao processo de construção de aprendizagens por meio da comunicação e da interação.

\section{A Tecnologia Assistiva e o Ensino de Língua Inglesa em Sala de Aula com Educação Inclusiva}

$\mathrm{O}$ avanço das tecnologias digitais trouxe consigo diversas ferramentas, que têm sido criadas para auxiliar os professores e alunos no processo de ensino e aprendizagem, de forma mais colaborativa, interativa e consistente. No âmbito da educação inclusiva, as tecnologias são vistas como uma oportunidade de se ensinar a língua inglesa de modo a ampliar a oportunidade de aprendizado e, também, desenvolver habilidades que poderão mudar a forma de reconhecer o mundo em sua língua materna e na língua inglesa (Martins, 2020).

Com esse propósito, os professores dessa disciplina podem fazer uso dos inúmeros recursos que a Tecnologia Assistiva apresenta. Ela é uma grande aliada para ajudar no desenvolvimento do público-alvo da Educação Especial e promover oportunidades de aprendizagem a todos os demais integrantes da turma igualmente. Contudo, o professor deve ficar atento às escolhas dos recursos necessários e apropriados ao seu público, já que, além de necessitarem estar relacionadas às habilidades, devem ser consideradas as idades de cada aluno. Ademais, o aluno poderá precisar de um tempo de adaptação ao recurso escolhido pelo professor. Em função disso, o contato com esse tipo de tecnologia deve ser inicializado o mais rápido possível.

Durante essa pesquisa, não foi encontrado nenhum tipo de Tecnologia Assistiva relacionada ao ensino de língua inglesa. Entretanto, as T.A. que existem podem ser adaptadas pelos professores dessa disciplina para esse fim. Dentre as possibilidades citadas neste estudo, temos a prancha, a qual auxilia as pessoas com problemas na fala a formar as palavras com o simples gesto de apontar, e o professor de inglês pode trabalhar um vocabulário específico fazendo uso dela. Outra possibilidade é o uso de equipamentos de voz, permitindo a comunicação do aluno por meio da voz robótica, ele podendo, assim, expressar-se, questionar, participar da aula. Entre as possibilidades, existem, também, outros recursos, como os aparelhos de surdez e os sistemas de alerta táctil-visual, que promovem a comunicação dos alunos com deficiência auditiva. Os teclados podem ser ampliados para o deficiente visual ou pode ser feito um escaneamento do material impresso pelo professor para convertê-lo em áudio. Em se tratando de alunos autistas, há filmes que podem ajudá-los a interagir socialmente.

Além desses recursos citados, foi observado, em uma editora de livros, em seu site, um link sobre acessibilidade, o qual o professor poderá oferecer aos alunos com deficiência uma melhor possibilidade de navegação. Nesse, na barra de acessibilidade, aparecem as possibilidades de atalhos de teclado sem a necessidade de uso do mouse, o que facilita a navegação. Nessa página, igualmente, aparecem as informações sobre acessibilidade do site e os recursos oferecidos. Um dos recursos oferecidos, pelo site, é destinado às pessoas que têm baixa visão, as quais empregam o recurso de alto contraste. Outro recurso disponibilizado, pela editora, é um mapa do site para que o aluno conheça toda a estrutura do site e consiga ir, diretamente, à página desejada. Essa editora não apresentou nenhum livro didático de língua inglesa em formato acessível. 
Dessa maneira, o professor de língua inglesa pode fazer uso de qualquer Tecnologia Assistiva em busca da atenção dos alunos que são públicos-alvo da Educação Especial, bem como proporcionar a eles uma melhor qualidade de ensino e uma maior interação dos alunos com algum tipo de deficiência e a turma em que eles se encontram inseridos. Neste contexto, Moresi (2018), afirma que os dispositivos tecnológicos contribuem para o aprendizado e para a participação independente na vida escolar e, também, na vida social dos alunos. Para tanto, o professor poderá fazer uso das T.A de forma adaptada, segundo seus interesses e as necessidades de seus alunos.

\section{Considerações Finais}

A inclusão de alunos com deficiência, na Rede Municipal de Ensino, requer muita atenção, desde a adaptação desses estudantes, da equipe diretiva, dos professores e dos funcionários da escola. As Tecnologias Assistivas, ao serem introduzidas no ambiente escolar, contribuirão para que os referidos alunos tenham uma boa participação e interação com os colegas e professores. Os mecanismos dessas tecnologias são de grande valia no processo ensino-aprendizagem dos alunos com necessidades educativas especiais, pois conferem a eles o direito de participarem, de aprenderem e de terem uma convivência educacional como qualquer outro aluno.

Vale lembrar que as Tecnologias Assistivas vão desde as tecnologias de ponta, até recursos, ferramentas e práticas educacionais ou materiais didáticos devidamente elaborados com a intenção de possibilitar a participação autônoma e efetiva do estudante que apresenta alguma dificuldade ao longo do seu percurso escolar. Todavia, para que se faça um uso adequado dessas tecnologias, é indispensável, sobretudo, destacar que seus recursos necessitam ser manejados de forma eficaz pelo corpo docente e que, de modo especial, os professores consigam adequar seus métodos ao contexto e às necessidades do aluno com algum tipo de deficiência. Existem muitas plataformas de ensino e muitas serão criadas, mas de nada servirão se o professor não fizer uso desses recursos tecnológicos com o conhecimento necessário de seu manuseio para que tenham condições de auxiliar os alunos, bem como de inovar suas aulas.

Seguem alguns exemplos de tecnologias assistivas que poderão auxiliar o professor, tais como os aplicativos educacionais, que em sua maioria, oferecem atividades de forma lúdica, com recursos coloridos e envolventes. Esses recursos instigam a curiosidade do aluno, proporcionando um aprendizado de maneira divertida. (Gonçalves, Cardoso, Amorim e Passos, 2020). A ludicidade e a interatividade despertam interesses, nos alunos, em aprender coisas novas e a relacionar os conceitos e conteúdos de forma significativa.

Igualmente, vale destacar que as Tecnologias Assistivas nem sempre estarão em telas ou softwares. Na verdade, elas podem ser simples adaptações, as quais auxiliem o aluno com deficiência em seu processo educativo, como amarrar sua mão ao lápis para que ele consiga escrever ou realizar a captação da sua voz a fim de que seja transformada em texto. De qualquer forma, existem inúmeros recursos tecnológicos, modernos e adaptados para pessoas com algum tipo de deficiência. A Tecnologia Assistiva, na escola, é, na verdade, uma busca do professor, por meio da sua criatividade, de alternativas que ajudem o aluno a realizar o que precisa ou deseja.

"Existe um número incontável de possibilidades, de recursos simples e de baixo custo que podem e devem ser disponibilizados nas salas de aula inclusivas, conforme as necessidades específicas de cada aluno com necessidades educacionais especiais, tais como: suportes para visualização de textos ou livros, fixação do papel ou caderno na mesa com fitas adesivas, engrossadores de lápis confeccionados de forma artesanal, substituição da mesa por pranchas de madeira ou acrílico fixadas na cadeira de rodas e inúmeras outras possibilidades. Tudo isso é Tecnologia Assistiva. Com muita frequência, a disponibilização de recursos e adaptações bastante simples e artesanais como estes, às vezes construídos pelos próprios professores, torna-se, para determinados alunos com deficiência, a diferença entre poder ou não estudar e aprender juntamente com seus colegas". (Galvão Filho, 2013) 
Ao mesmo tempo, é uma busca por estratégias que envolvam o aluno ativamente, ou seja, que consigam retirar o aluno com necessidade educacional especial da zona de conforto com o intuito de que possa agir e interagir na turma em que se encontra. Portanto, o professor de Língua Inglesa que, possui em sua sala de aula alunos que são públicos-alvo da Educação Especial, pode inserir a Tecnologia Assistiva como forma de enriquecer suas aulas e proporcionar, a esses alunos, maior participação nas atividades, a interação social deles e, acima de tudo, terá condições de ajudá-los a desenvolver suas autonomias. Além disso, com o uso desse tipo de tecnologia, os alunos terão condições de participar ativamente das aulas, seja nos momentos de descontração, de aprendizado, de diálogo, de leitura ou de produção de atividades referentes ao idioma em questão.

Em outras palavras, a tecnologia assistiva aliada à educação vai além do auxílio ao aluno a realizar as tarefas pretendidas . $\mathrm{Na}$ TA, existem meios que proporcionam o aluno a ser e atuar de forma construtiva no seu desempenho e desenvolvimento. (Brito \& Farias, 2016).

Em vista disso, sugere-se aos próximos pesquisadores que ampliem os conhecimentos adquiridos nesse artigo e procurem recursos da tecnologia assistiva direcionados a casos específicos dentro da Educação especial, pois além de proporcionarem autonomia e independência a esses alunos, irão ajudá-los a manter a atenção e interesse em aprender.

\section{Referências}

Alves, L. J. (2020) O uso das tecnologias digitais para o ensino de língua inglesa em tempos de pandemia. Cabedelo https://repositorio.ifpb.edu.br/bitstream/177683/1164/1/TCC\%20com\%20ficha\%20catalogr\%c3\%a1fica\%20-\%20Luedna\%20Janu\%c3\%a1rio\%20Alves.pdf

Autismo em Dia. https://www.autismoemdia.com.br/blog/autismo-e-tecnologia-conexao-que-ajuda-pessoas-com-tea/.

Bolg Freedom. https://blog.freedom.ind.br/tecnologia-assistiva-como-promover-a-inclusao-da-pessoa-com-deficiencia.

BRASIL. CAT, 2007c. Ata da Reunião VII, de dezembro de 2007, Comitê de Ajudas Técnicas, Secretaria Especial dos Direitos Humanos da Presidência da República (CORDE/SEDH/PR). https://www.assistiva.com.br/Ata_VII_Reuni\%C3\%A3o_do_Comite_de_Ajudas_T\%C3\%A9cnicas.pdf.

BRASIL. Ministério da Educação: Base Nacional Comum Curricular.https://www.olideremmim.com.br/blog/acolhimento-a-ferramenta-da-bncc-na-educacaoespecial/

BRASIL. Ministério da Educação: Lei Nº 9.394, de 20 de dezembro de 1996. Cap. IV. http://www.planalto.gov.br/ccivil_03/LEIS/L9394.htm.

BRASIL. Ministério da Educação: Lei No 13.146, de 06 de junho de 2015. Cap. V. http://www.planalto.gov.br/civil_03/_ato2015-2018/2015/lei/113146.htm.

BRASIL. Ministério da Cducação: Câmara dos Peputados. Medida https://www.camara.leg.br/proposicoesWeb/fichadetramitacao?idProposicao=2242413\#: :text=MPV\%20934\%2F2020\&text=Estabelece\%20normas\%20exce pcionais $\% 20$ sobre $\% 20$ o,6\%20de $\% 20$ fevereiro $\% 20 \mathrm{de} \% 202020$.

Brito, R. R.; Silva, A. P.; Farias, A. L.; Almeida, L. R. \& Silva, P. R. P. (2016). tecnologias assistivas na educação: Ferramentas Facilitadoras de Inclusão Digital. II CINTEDI: II Congresso Internacional de Educação Inclusiva. https://editorarealize.com.br/editora/anais/cintedi

Darido, M. C.; Bizelli, J. L. (2015). Inovações tecnológicas e contexto escolar: reflexões necessárias. Revista Ibero-Americana de Estudos em Educação, vol. 10, núm. 1, enero-marzo, pp. 50-66 Universidade Estadual Paulista Júlio de Mesquita Filho. https://www.redalyc.org/pdf/6198/619866418005.pdf

Gabriel, M. (2013). Educar: a (r)evolução digital na educação. 1. ed. - São Paulo: Saraiva.

Galvão Filho, T. (2012). Tecnologia Assistiva: favorecendo o desenvolvimento e a aprendizagem em contextos educacionais inclusivos. In: GIROTO, C. R. M.; Poker, R. B.; Omote, S. (Org.). As tecnologias nas práticas pedagógicas inclusivas. Marília/SP: Cultura Acadêmica, p. 65-92.

Galvão Filho, T. (2013). Tecnologia Assistiva e Educação. In: Educação inclusiva, tecnologia e tecnologia assistiva/ E24E organização, Rita de Cácia Santos Souza, Josilene Souza Lima Barbosa.Aracaju: Criação, P.13-36. https://editoracriacao.com.br/wp-content/uploads/2015/11/inclusiva.pdf.

Gonçalves R. F.; Cardoso J. F. Amorim R. X. \& Passos, O. M. (2020). Ferramentas Assistivas no Ensino e Aprendizagem

Pessoas com Síndrome de Down: Um Mapeamento Sistemático. IX Congresso Brasileiro de Informática na Educação (CBIE 2020)Anais do XXXI Simpósio Brasileiro de Informática na Educação (SBIE 2020)652 DOI: 10.5753/cbie.sbie.2020.652. https://sol.sbc.org.br/index.php/sbie/article/view/12821/12675

Martins, S. T. A. (2020). Dinamizando o ensino de inglês em tempos de pandemia: experiências de ensino através do Instagram de um projeto de extensão. https://periodicos2.uesb.br/index.php/folio/article/view/7423/5570.

Miranda, M. V. C. (2020) et al. Educação inclusiva, utilizando recursos da tecnologia da informação, nas escolas públicas de areia-pb, em tempos de pandemia. Anais do V CONAPESC. Campina Grande: Realize Editora.

Moresi, E. A. D. (2018). Tecnologia Assistiva e Autismo. Memorias de la Octava Conferencia Iberoamericana de Complejidad, Informática y Cibernética (CICIC). https://www.iiis.org/CDs2018/CD2018Spring/papers/CB032HE.pdf 
Research, Society and Development, v. 11, n. 1, e59711125469, 2022

(CC BY 4.0) | ISSN 2525-3409 | DOI: http://dx.doi.org/10.33448/rsd-v11i1.25469

Santana, C.; Santos, A.; \& Pereira.(2012) A inclusão escolar: a utilização da tecnologia assistiva na educação regular. $3^{\circ}$ Simpósio de Educação e Comunicação. Anais..http://atividadeparaeducacaoespecial.com/wp-content/uploads/2015/07/tecnologia-assistiva-no-ensino-regular.pdf.

Silva, A. J. F.; Pereira, B. K. M., Oliveira, J. A. M.; Surdi, A. C., \& Araújo, A. C.. (2020). A adesão dos alunos às atividades remotas durante a pandemia: realidades da educação física escolar. Corpoconsciência, 24(2), 57-70 .https://periodicoscientificos.ufmt.br/ojs/index.php/corpoconsciencia/article/view/10664.

Vieira, A. A.; Souza, C. J. A utilização das tecnologias assistivas para alunos surdos em tempos de pandemia: um estudo introdutório. https://www.revistas.ufg.br/rir/article/view/65382/35629.

Wikipédia. https://pt.wikipedia.org/wiki/Wikip\%C3\%A9dia:P\%C3\%A1gina_principal. 